\title{
La presencia de un modelo de gobernanza en la gerencia estratégica de proyectos: caso aplicable a empresas de consumo masivo
}

\author{
The presence of a governance model in project management: \\ the case of mass consumption companies
}

Recibido: 15-03-2020 • Aprobado: 09-11-2020 • Página inicial: 69 - Página final: 105

\author{
Carlos Alberto Restrepo Carvajal* \\ Simón Andrés Ramos Sierra**
}

\begin{abstract}
Resumen: este artículo constituye una propuesta metodológica para desarrollar una oficina de gerenciamiento de proyectos que articule la estrategia y la gestión de proyectos desde la perspectiva de un modelo de gobernanza claro y efectivo para el sector de consumo masivo. La metodología utilizada se fundamentó en una investigación de tipo exploratorio-deductivo debido a que, a partir de una conceptualización general, soportada en un análisis documental y perceptual, se estableció el diseño de la oficina de gerenciamiento de proyectos. Además, se presenta una propuesta técnica para el entendimiento y la imbricación entre la estrategia organizacional y la gestión de proyectos como generadoras de valor para los grupos de interés. Por otra parte, se definen y desarrollan: un cuadro de mando integral para gestionar proyectos, un esquema de selección y priorización de proyectos alineado con la estrategia organizacional y un despliegue descriptivo de los beneficios de la aplicación del modelo de gobernanza.
\end{abstract}

Palabras clave: estrategia; gerencia; gobernanza; organización; proyectos.

\begin{abstract}
This article constitutes a methodological proposal to develop a project management office that articulates strategy and project management from the perspective of a clear and effective governance model for the mass consumer sector. The methodology used was based on an exploratory-deductive type of research from a general conceptualization, supported by a documentary and perceptual analysis, to establish the design of the project management office. In addition, a technical proposal is presented for the understanding and interweaving between organizational strategy and project management as generators of value for stakeholders. On the other hand, the following topics are defined and developed through the proposal: a balanced scorecard to manage projects, a project selection and prioritization scheme aligned with the organizational strategy and a descriptive display of the benefits of applying the governance model.
\end{abstract}

Keywords: Strategy; management; governance; organization; projects.

JEL: M10 - M13 - M19

\footnotetext{
* Magíster en Administración (MBA), Magíster en Ingeniería, PhD, Medellín-Colombia.

carlos.restrepo.carvajal@gmail.com

ORCID: https://orcid.org/0000-0002-1889-3340

** Magíster en Administración (MBA), Universidad EAFIT, Medellín-Colombia.

siandramo@gmail.com

ORCID: https://orcid.org/0000-0002-4547-0976
} 


\section{A presença de um modelo de governança na gestão estratégica de projetos: um caso aplicável a empresas de consumo massivo}

Resumo: este artigo constitui uma proposta metodológica para o desenvolvimento de um escritório de gerenciamento de projetos que articule a estratégia e a gestão de projetos na perspectiva de um modelo de governança claro e eficaz para o setor de consumo de massa. A metodologia utilizada baseou-se no tipo de pesquisa exploratóriodedutiva, pois, a partir de uma conceituação geral, apoiada em uma análise documental e perceptual, foi estabelecido o desenho do escritório de gerenciamento de projetos. Além disso, é apresentada uma proposta técnica para compreensão e entrelaçamento entre estratégia organizacional e gestão de projetos como geradores de valor para as partes interessadas. Por outro lado, são definidos e desenvolvidos: um balanced scorecard para gestão de projetos, um esquema de seleção e priorização de projetos alinhado à estratégia organizacional e uma apresentação descritiva dos benefícios da aplicação do modelo de governança.

Palavras-chave: estratégia; gestão; governança; organização; projetos. 


\section{Introducción}

La gerencia estratégica de proyectos tiene como objetivo principal enlazar la gestión de proyectos, programas y portafolios con la gestión estratégica. Para efectos del ámbito empresarial, dicha alineación permite que la estrategia organizacional (corporativa o competitiva) sea desarrollada, materializada y desplegada a través de proyectos que permitan la gestión de planes realistas y coherentes con las necesidades y realidades organizacionales para que las empresas alcancen sus metas. La investigación se direccionó hacia el sector de consumo masivo dado que en él se presentan volúmenes importantes de proyectos, derivados de los desarrollos, las implementaciones y los cambios que presentan el entorno cambiante y acelerado; aunado al hecho de que, en dicho sector, las investigaciones y aplicaciones en este campo son diversas e imprecisas, por lo que la propuesta busca dar un marco general aplicable para empresas de este tipo. Además, en esta propuesta se incorpora la gestión de los grupos de valor, como aliados estratégicos para el posicionamiento de la gestión de proyectos en las compañías de consumo masivo.

El posicionamiento de la gestión de proyectos en el entorno, a través de las capacidades estratégicas, tácticas y operativas, permite generar un relacionamiento con en el consumidor más fuerte, derivando en mayores beneficios para los grupos de valor. De igual manera, una adecuada gestión de proyectos permea las decisiones organizacionales, considerando líneas base y pronósticos.

Para el desarrollo de una cultura de gerencia estratégica de proyectos, es necesario contar con una estructura capaz de soportar y garantizar la implementación de la metodología, los procesos, las herramientas y demás elementos requeridos para agilizar, flexibilizar y simplificar las decisiones en la organización. En este sentido, se potencia la sostenibilidad y los principios de valor compartido, mediante la implementación de una oficina de gerenciamiento de proyectos, que logra los resultados esperados y alcanza su éxito asociado con un modelo de gobernanza aprobado y apalancado en los más altos niveles directivos de la organización y desplegados a través de las políticas de la empresa.

La gerencia estratégica de proyectos focaliza sus esfuerzos en que la gestión soporte la ejecución de la estrategia de una organización como un proceso de negocio clave, que le permita a la compañía implementar sistemas que generen valor (Srivannaboon \& Milosevic, 2006). En el papel, las estrategias de la organización se deberían ejecutar a través de proyectos; no obstante, en la práctica, esta premisa dista de la realidad, debido a que es difícil pasar de una 


\section{Contexto pestroo, c.y yeamos s. S.}

idea a un grupo de acciones que permita definir los proyectos necesarios para ejecutar la estrategia (Crawford et al., 2008).

De acuerdo con el Project Management Institute (PMI), cada vez más las organizaciones reconocen que la gestión de portafolios puede ayudarles a tomar las decisiones que los diferencian de sus competidores, $\mathrm{y}$, por ende, les permitan incrementar su competitividad. Además, indica que, al fomentar la comprensión de la gestión de portafolios, programas y proyectos entre los directivos, las organizaciones aumentan su capacidad para garantizar que los proyectos y los programas cumplan la estrategia organizacional (PMI, 2013). A la luz de lo anterior, es evidente el reto organizacional que tienen las organizaciones, en el que se refleja una desarticulación entre los niveles estratégico y táctico, lo que impide la generación de valor y relacionamiento con grupos de interés; también demuestra la carencia de un modelo efectivo de gobernanza que permita trascender hacia una gerencia estratégica de proyectos.

En la búsqueda de investigaciones realizadas sobre gobernanza en los últimos años, lideradas desde los puntos de vista de diferentes disciplinas de múltiples corrientes de investigación, se hace necesaria la revisión de definiciones que contengan elementos de supervisión y dirección. Si bien existen varias definiciones en uso, cada una está asociada con una corriente de investigación en particular y los investigadores explican con claridad cómo se vincula lo que están estudiando con dichas corrientes. Los estudios recientes están comenzando a extender la gobernabilidad como una necesidad en todas las organizaciones, en lugar de acotarla solo a su parte superior (PMI, 2016).

La investigación sobre gobernanza en revistas relacionadas con proyectos tiende a utilizar una amplia variedad de definiciones y tendencias y, a menudo, combina la gobernabilidad con la administración. Existe confusión entre la gobernanza de un solo proyecto, la que se ejerce sobre un proyecto, la de la gestión de proyectos y la de redes complejas de organizaciones (PMI, 2016).

A partir de 2014, los estándares del PMI proporcionan varias definiciones en relación con los diferentes niveles de gestión de proyectos que operan en las organizaciones. Dada la necesidad reconocida de adaptar la gobernanza a la organización para la que fue diseñada, y si se piensa en Proyectos, Portafolios y Programas (PPP) que se administran en diferentes niveles de una organización, este enfoque puede estar justificado. Sin embargo, los estándares del PMI continúan la tendencia de investigación de combinar actividades de gestión y gobernabilidad (PMI, 2016). 
Existe muy poca evidencia empírica sobre la gobernanza específica de PPP fuera de las revistas relacionadas con proyectos, excepto en las revistas de Tecnología de Información (TI). Casi no hay evidencia empírica de la efectividad de la gobernanza de PPP, aparte de los comités de patrocinio y dirección. Existe una evidencia empírica de gran cantidad de información y en aumento de que el patrocinio efectivo del proyecto afecta tanto su gestión como su éxito empresarial. Hay un campo creciente de literatura empírica que explora el papel del comité directivo, aunque los resultados son ambiguos, porque hay confusión de gobierno y gestión. Todo el mundo en la literatura del proyecto parece suponer que usa el término "gobernanza" y no define su significado o usa su propia definición en lugar de basarse en otros y, en forma específica, no se basa en la literatura de administración general. Al parecer desde 2014 ha aumentado el enfoque hacia la gobernabilidad y los esfuerzos para producir evidencias de su aplicación (PMI, 2016).

Frente a la escasez del trabajo empírico relacionado con gobernanza de proyectos, en la mayoría de las investigaciones se sugiere que las relaciones estructurales funcionen de la siguiente manera:

- El gobierno corporativo se centre en la supervisión y dirección, a través del mecanismo de la gestión de portafolios y la creación de marcos de tipo Organizational Project Management (OPM) o Dirección Organizacional de Proyectos.

- Los patrocinadores, los comités directivos y organismos de gestión de portafolio (de proyectos y programas) proporcionen el vínculo entre la gestión de proyectos y la gestión estratégica y gobernanza corporativa.

- La gestión de proyectos y programas tenga nivel de gestión.

Los múltiples antecedentes, interrogantes y problemáticas llevan a que el objetivo principal de este trabajo sea proponer el desarrollo de una oficina de gerenciamiento de proyectos, a través de un modelo de gobernanza para el sector de consumo masivo, que materialice la gerencia estratégica de proyectos a partir de sinergias, generación de valor y maximización de la efectividad en la gestión organizacional.

Lo anterior soportado por los siguientes objetivos específicos:

- Definir un modelo de gobernanza de proyectos para el sector de consumo masivo. 


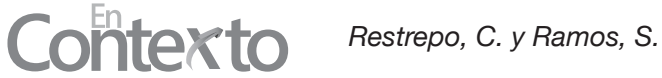

- Estructurar una oficina de gerenciamiento de proyectos en el sector de consumo masivo.

- Definir un cuadro de mando integral para proyectos del sector de consumo masivo.

- Desarrollar un esquema de selección y priorización de proyectos para el sector de consumo masivo.

- Detallar los beneficios de aplicar el modelo de gobernanza para desarrollar una oficina de gerenciamiento de proyectos en el sector de consumo masivo.

\section{Marco teórico}

\section{Gestión de proyectos}

Un proyecto es un esfuerzo temporal que se lleva a cabo para crear un producto, servicio o resultado único. La naturaleza temporal de los proyectos, implica que estos tengan un principio y final definidos. El final se alcanza cuando se logran los objetivos del proyecto, cuando se termina el proyecto, porque sus objetivos no se cumplen o no pueden ser cumplidos o cuando ya no existe la necesidad que dio origen al proyecto (PMI, 2017a).

El Project Management Institute es una organización fundada en 1969, que busca madurar la profesión de la gerencia de proyectos y, a través de ella, mejorar el éxito de las empresas. La guía del PMBOK ${ }^{\circledR}$ (PMI, 2017a) es una de las herramientas más conocidas y utilizadas de la entidad mencionada y presenta un conjunto de buenas prácticas que han comprobado su valor y su utilidad en la aplicación de la gerencia de proyectos. Esta guía se divide en las siguientes diez áreas del conocimiento, utilizadas por lo general en la ejecución de los proyectos:

- Gestión de la integración del proyecto.

- Gestión del alcance del proyecto.

- Gestión del cronograma del proyecto.

- Gestión de los costos del proyecto.

- Gestión de la calidad del proyecto.

- Gestión de los recursos del proyecto.

- Gestión de las comunicaciones del proyecto.

- Gestión de los riesgos del proyecto.

- Gestión de las adquisiciones del proyecto.

- Gestión de los interesados del proyecto. 
Una de las aproximaciones mediante la que se puede enlazar la gestión de proyectos con la estrategia organizacional es la implementación de la gestión de portafolios (Wessels, 2007). Para entender en forma más clara la gerencia estratégica de proyectos y la gestión de portafolios, primero se debe entender lo que son "los programas, que son un grupo de proyectos, programas secundarios y actividades de programas relacionados cuya gestión se realiza de manera coordinada para obtener beneficios que no se obtendrían si se gestionaran de forma individual" (PMI, 2017b, p.23), mientras que "los portafolios son una colección de proyectos, programas, portafolios secundarios y operaciones gestionados como un grupo para alcanzar los objetivos estratégicos" (PMI, 2017b, p.23). Por lo anterior, el portafolio se consolida como un conjunto de elementos que reflejan y afectan los objetivos estratégicos de la organización.

\section{Oficina de gerenciamiento de proyectos}

En las organizaciones se constituye un área encargada de la gerencia estratégica de proyectos, bautizada como la Oficina de Gestión de Proyectos (PMO), que es una estructura de gestión que estandariza los procesos de gobierno relacionados con el proyecto y hace más fácil compartir recursos, metodologías, herramientas y técnicas. Las responsabilidades de una PMO pueden abarcar desde el suministro de funciones de soporte para la dirección de proyectos hasta la responsabilidad de la propia dirección de uno o más proyectos, tomar decisiones clave a lo largo del ciclo de vida, hacer recomendaciones, poner fin a proyectos o tomar otras medidas (PMI, 2017a).

Una PMO es la entidad organizacional que define y mantiene los estándares de procesos relacionados con la gestión de portafolios, programas y proyectos. La PMO puede ser el implementador o el destinatario de la Gestión Organizacional de Proyectos (OPM), dado que pueden existir diferentes tipos de PMO dentro de una organización que difieran en alcance, autoridad, jerarquía de informes y responsabilidades (PMI, 2016).

Dependiendo de las necesidades de la organización, la cultura y estructura, la PMO puede operar en un nivel empresarial, de unidad de negocios, división o funcional (por ejemplo, TI, I + D y mercadeo). También puede haber una PMO de propósito específico según la necesidad de la organización. Por ejemplo, se puede formar una PMO de Planificación de Recursos Empresariales (ERP) para administrar la implementación del ERP, que puede afectar a todas las personas de la empresa, debido a las implicaciones de los recursos humanos y procesos financieros. El establecimiento de una PMO resalta la necesidad de un marco 


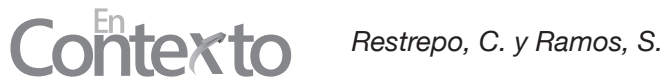

de gobierno estructurado y formalizado que no existía y la PMO en sí puede asumir funciones de gobierno (PMI, 2016).

Una PMO soporta el gobierno de OPM de las siguientes maneras:

- Desarrollar marcos de gobierno, jerarquías y relaciones de organización.

- Supervisar la alineación estratégica del portafolio, el programa y proyecto, y facilitar las decisiones clave.

- Supervisar la integración del portafolio, el programa y los procesos del proyecto.

- Alinear y optimizar componentes de cartera, programa y proyecto con el fin de apoyar propuestas de componentes y evaluaciones.

- Facilitar la priorización, autorización y asignación de recursos.

- Desarrollar y mantener estándares y metodologías de gestión de portafolios, programas y proyectos.

- Negociar y coordinar recursos entre la cartera, el programa y los componentes del proyecto o entre portafolios.

- Evaluar y escalar problemas y riesgos.

- Llevar a cabo revisiones detalladas de portafolios, programas y proyectos.

- Monitorear el portafolio, el programa y desempeño del proyecto (real versus planeado), y los indicadores clave de desempeño.

- Realizar auditorías legales, regulatorias, ambientales, financieras y de cumplimiento.

- Hacer seguimiento del cumplimiento de las políticas y los procedimientos.

- Facilitar el compromiso y el acuerdo de las partes interesadas en toda la organización.

- Asignar gerentes de portafolio, programa y proyecto para implementarlos.

Según Gerard Hill (2004), el rol de la PMO es entender y aplicar las prácticas modernas en la gestión de proyectos; además, adaptar e integrar los intereses comerciales con los esfuerzos de gestión de proyectos en la organización; así las funciones de la PMO se clasifican en cinco etapas (Tabla 1). 
Tabla 1

Etapas de una PMO, según Hill (2004)

Alineación estratégica

Madurez del negocio Etapa 5

\begin{tabular}{lll}
\hline \multicolumn{2}{c}{ Soporte en el proceso } & Etapa 4 \\
\hline Control del proceso & Etapa 3 & \\
\hline
\end{tabular}

\begin{tabular}{|c|c|c|c|c|}
\hline $\begin{array}{l}\text { Supervisión } \\
\text { del proyecto }\end{array}$ & \multirow[t]{2}{*}{ Etapa 2} & & & \\
\hline \multicolumn{4}{|l|}{ Etapa 1} & \\
\hline OFICINA DE & $\mathrm{PMO}$ & PMO & PMO & CENTRO DE \\
\hline PROYECTOS & BÁSICA & ESTÁNDAR & AVANZADA & EXCELENCIA \\
\hline $\begin{array}{l}\text { Generar los } \\
\text { entregables del } \\
\text { proyecto según } \\
\text { cronograma, } \\
\text { con buen uso } \\
\text { de recursos. }\end{array}$ & $\begin{array}{l}\text { Provee una } \\
\text { metodología } \\
\text { de gerencia } \\
\text { de proyectos } \\
\text { estándar y } \\
\text { repetitiva } \\
\text { para uso de } \\
\text { todos los } \\
\text { proyectos. }\end{array}$ & $\begin{array}{c}\text { Establece } \\
\text { capacidades e } \\
\text { infraestructura } \\
\text { para apoyar } \\
\text { y gobernar } \\
\text { un ambiente } \\
\text { cohesivo en } \\
\text { proyectos. }\end{array}$ & $\begin{array}{c}\text { Aplica } \\
\text { capacidades } \\
\text { intensas y } \\
\text { globales en } \\
\text { gerencia de } \\
\text { proyectos para } \\
\text { alcanzar los } \\
\text { objetivos } \\
\text { del negocio. }\end{array}$ & $\begin{array}{c}\text { Gestiona mejora } \\
\text { continua y } \\
\text { colaboración } \\
\text { entre } \\
\text { departamentos } \\
\text { para alcanzar } \\
\text { las metas } \\
\text { estratégicas } \\
\text { del negocio. }\end{array}$ \\
\hline $\begin{array}{l}\text { Uno o más } \\
\text { proyectos. }\end{array}$ & $\begin{array}{l}\text { Múltiples } \\
\text { proyectos. }\end{array}$ & $\begin{array}{l}\text { Múltiples } \\
\text { proyectos. }\end{array}$ & $\begin{array}{l}\text { Múltiples } \\
\text { proyectos. }\end{array}$ & $\begin{array}{l}\text { Múltiples } \\
\text { proyectos. }\end{array}$ \\
\hline \multirow[t]{5}{*}{$\begin{array}{l}\text { Un gerente de } \\
\text { proyecto. }\end{array}$} & $\begin{array}{c}\text { Múltiples } \\
\text { gerentes } \\
\text { de proyectos. }\end{array}$ & $\begin{array}{c}\text { Múltiples } \\
\text { gerentes } \\
\text { de proyectos. }\end{array}$ & $\begin{array}{c}\text { Múltiples } \\
\text { gerentes } \\
\text { de proyectos. }\end{array}$ & $\begin{array}{c}\text { Múltiples } \\
\text { gerentes } \\
\text { de proyectos. }\end{array}$ \\
\hline & $\begin{array}{c}\text { Un gerente } \\
\text { de programa. }\end{array}$ & $\begin{array}{l}\text { Múltiples } \\
\text { gerentes de } \\
\text { programas. }\end{array}$ & $\begin{array}{l}\text { Múltiples } \\
\text { gerentes de } \\
\text { programas. }\end{array}$ & $\begin{array}{l}\text { Múltiples } \\
\text { gerentes de } \\
\text { programas. }\end{array}$ \\
\hline & $\begin{array}{c}\text { Grupo con } \\
\text { dedicación } \\
\text { parcial para la } \\
\text { PMO. }\end{array}$ & $\begin{array}{c}\text { Grupo con } \\
\text { dedicación } \\
\text { total para la } \\
\text { PMO. }\end{array}$ & $\begin{array}{c}\text { Gerente } \\
\text { de la PMO. }\end{array}$ & $\begin{array}{c}\text { Gerente } \\
\text { de la PMO. }\end{array}$ \\
\hline & & & $\begin{array}{c}\text { Grupo con } \\
\text { dedicación total } \\
\text { para la PMO } \\
\text { para funciones } \\
\text { técnicas y de } \\
\text { apoyo. }\end{array}$ & $\begin{array}{c}\text { Grupo con } \\
\text { dedicación total } \\
\text { para la PMO } \\
\text { para funciones } \\
\text { técnicas. }\end{array}$ \\
\hline & & & & $\begin{array}{c}\text { Personal de } \\
\text { apoyo a la } \\
\text { PMO en toda la } \\
\text { organización. }\end{array}$ \\
\hline
\end{tabular}

Traducción de texto original en inglés de Hill (2004, p.46). 


\section{Contexto pestroo, c.y yeamos s. S.}

Para complementar las definiciones de Hill (2004), se relacionan las siguientes clasificaciones para establecer una oficina de gerenciamiento de proyectos a partir del alcance, nivel de responsabilidad y control requeridos, que fueron definidas por Casey \& Peck (2001):

- Estación meteorológica (weather station): este modelo rastrea y reporta eventos de los proyectos sin influir en forma directa en ellos, es decir, comunica los diversos aspectos de la ejecución del proyecto a los diferentes interesados. Es usual el uso de la metodología de Valor Ganado para la generación de alertas tempranas. Las funciones básicas de una PMO del tipo de la estación meteorológica pasan por dar respuesta a las siguientes preguntas para cada uno de los proyectos en curso:

$\checkmark$ ¿Cuál es el progreso del proyecto? (por lo general este reporte se hace para los hitos establecidos en la Estructura de División del Trabajo (EDT) y con posterioridad en el cronograma).

$\checkmark$ ¿Cuál porcentaje del presupuesto del proyecto se ha ejecutado?

$\checkmark$ ¿Cuál porcentaje del presupuesto se debería haber ejecutado para el momento actual del proyecto?

$\checkmark$ ¿Cuáles son los principales riesgos que afronta el proyecto en la actualidad?

- Torre de control (control tower): ejerce un poco más de control sobre los proyectos, mediante las diferentes etapas de los respectivos ciclos de vida. Estandariza políticas y procedimientos para gobernar la planificación, ejecución y gerencia de proyectos. De igual manera, sugiere la creación de un comité para seleccionar y definir estándares sobre los proyectos. Las funciones básicas de una PMO del tipo de la torre de control son establecer las normas para la gestión de proyectos, brindar apoyo a los gerentes de proyectos sobre la forma correcta de seguir las normas, cumplirlas y mejorar las establecidas.

- Agrupación de recursos (resource pool): corresponde a un inventario de recursos disponibles para los jefes y gerentes de proyectos en el desarrollo de los correspondientes ciclos de vida. Las funciones básicas de una PMO del tipo de agrupación de recursos son brindar a la organización un grupo de directores de proyectos calificados, capacitados y aptos para el tipo de proyectos a los que se asignan y asegurar que estos se realicen de forma correcta. 


\section{Criterios para la selección y priorización de proyectos}

La selección y priorización de proyectos, en los ámbitos estratégico y operativo, es a menudo la diferencia entre el éxito y el fracaso de una empresa y es, a su vez, la función esencial de una PMO estándar. Por ello, toda organización necesita una serie de criterios básicos, porque sin ellos es complejo establecer prioridades de manera efectiva. Los criterios definidos en una priorización establecen en orden jerárquico los proyectos que garantizan mayores beneficios, asociando los recursos necesarios, restricciones, supuestos y externalidades.

La forma más conocida para seleccionar los proyectos que hacen parte de un portafolio que responda a la estrategia organizacional es a través de un comité corporativo, que establezca criterios ponderados para tener la capacidad de distinguir entre el valor que otorga un proyecto de un área $u$ otra, o un proyecto que involucre dos áreas o más, frente a uno de una sola área, de modo que se disminuya la subjetividad. Para la selección y priorización de proyectos se consideran cinco grupos de técnicas, entre los cuales se propone para cada uno de ellos una subclasificación (Fernández Carazo et al., 2008):

- Modelos económicos: Valor Actual Neto (VAN) de los beneficios netos de un proyecto, Tasa Interna de Rentabilidad (TIR), período mínimo de reembolso o recuperación de la inversión y ratio entre beneficio y costo.

- Modelos de teoría de la decisión: tablas de decisión y árboles de decisión, que muestran la gama de posibles resultados y decisiones posteriores realizadas después de la resolución inicial.

- Métodos basados en pesos y ordenación (ranking): estos modelos permiten determinar una jerarquía u orden (ranking) de preferencia de los proyectos candidatos con base en un conjunto de criterios, para que, con posterioridad, el agente decisor, en función de los recursos disponibles, seleccione los proyectos en orden hasta agotar los recursos (Fernández Carazo et al., 2008):

$\checkmark$ Modelos comparativos: conteo de la dominancia y método de la escala anclada.

$\checkmark$ Modelos de puntaje: lista de chequeo, modelos de puntaje tradicional, análisis de utilidad multiatributo y Modelo de Jerarquía Analítica (AHP).

$\checkmark$ Otras técnicas: análisis de conglomerados y Análisis Envolvente de Datos (DEA). 


\section{Contexto pestroo, c.y yeamos s. S.}

$\checkmark$ Modelos de programación matemática: con estos modelos, de manera genérica, se obtiene una o más soluciones que obedezcan las restricciones establecidas y optimicen la/s función/es objetivo/s (Fernández Carazo et al., 2008). Entre ellos que se distinguen: programación monobjetivo, programación multiobjetivo y programación por metas.

\section{Gobernanza de proyectos}

Existen diversos tipos de gobernanza, incluidas la gobernanza organizacional, la de la dirección organizacional de proyectos (OPM) y la de portafolios, programas y proyectos. La gobernanza organizacional es una forma estructurada de proporcionar dirección y control a través de políticas y procesos para cumplir las metas estratégicas y operativas. Por lo general, la gobernanza organizacional está a cargo de una junta directiva para garantizar la rendición de cuentas, la imparcialidad y transparencia a sus interesados. Los principios, decisiones y procesos de la gobernanza organizacional pueden influir y afectar la de portafolios, programas y proyectos de las siguientes maneras (PMI, 2017a):

- Para hacer cumplir los requisitos legales, regulatorios, normativos y de cumplimiento.

- Para definir responsabilidades éticas, sociales y ambientales.

- Para especificar las políticas operativas, legales y de riesgo.

Según el PMBOK® ${ }^{\circledR}$ (PMI, 2017a), la gobernanza del proyecto consiste en el marco, las funciones y los procesos que guían las actividades de dirección del proyecto, con el fin de crear un producto, servicio o resultado único para cumplir las metas organizacionales, estratégicas y operativas. La gobernanza del proyecto incluye guiar y supervisar la gestión del trabajo del proyecto, asegurar la adhesión a las políticas, los estándares y guías, establecer roles, responsabilidades y autoridades de la gobernanza, tomar decisiones sobre escalamiento de riesgos, cambios y recursos (por ejemplo: en equipo, financieros, físicos e instalaciones), asegurar el adecuado involucramiento de los interesados y monitorear el desempeño.

Por su parte, la gobernanza de proyectos supone el qué (la toma de decisiones, emisión de orientaciones y supervisión y aseguramiento de la gestión), es decir, procesos de control y orientación para los proyectos; la dirección o gerenciamiento de proyectos, de otro lado, suponen el cómo (la organización, la gestión, hacer el trabajo y generar resultados), es decir, procesos de inicio, planeación, ejecución, monitoreo y control y cierre para los proyectos (Figura 1). 
Para definir un modelo de gobernanza efectivo se hace necesario tener como insumos los objetivos y las metas estratégicas organizacionales, la estructura organizacional, los órganos de gobierno, las políticas y los procedimientos, las necesidades y metas organizacionales adoptadas por el gobierno corporativo, la metodología de gestión de portafolios, programas y proyectos, el estado del portafolio; el inventario de componentes y su estado y el conocimiento de los diferentes patrocinadores de proyectos, programas y portafolios (PMI, 2016).

Para darle vida al modelo de gobernanza se requiere una estructura compuesta por:

a) Un órgano de gobernanza, que se caracteriza por ser un grupo temporal o permanente, compuesto por miembros de áreas de responsabilidad y con autoridad para orientar y tomar decisiones sobre portafolios, programas y proyectos.

b) Un marco de gobernanza, compuesto por cuatro ámbitos de gobernanza con funciones, procesos y actividades para portafolios, programas y proyectos: alineamientos, riesgos, comunicación y desempeño.

c) Un ámbito de gobernanza, que es el conjunto de funciones realizadas por un individuo, grupo u organización dirigido a un área específica de gobernanza.

d) Una función de gobernanza, que es el conjunto de procesos (supervisión, control, integración y toma de decisiones) relacionados entre sí y a través de ámbitos de gobernanza que se desarrollan con la finalidad de brindar soporte en la gestión de portafolios, programas y proyectos (PMI, 2016).

\begin{tabular}{|c|c|c|c|}
\hline & Gobernanza de proyectos & Actividad o entregable & Dirección de proyectos \\
\hline 1. & Define y aprueba & 1. Estrategia, metas y objetivos & 1. Recomienda e implementa \\
\hline 2. & Hace y determina & 2. Política & $\begin{array}{l}\text { 2. Comunica y establece } \\
\text { procedimientos }\end{array}$ \\
\hline 3. & Establece y aprueba & Marco de gobernanza & 3. Identifica y documenta \\
\hline 4. & Garantiza participación & Partes interesadas & Identifica y gestiona \\
\hline 5. & $\begin{array}{l}\text { Determina y aprueba criterios de } \\
\text { priorización }\end{array}$ & 5. Priorización & Prioriza componentes \\
\hline 6. & Identifica, asegura y comunica & 6. Alineamiento estratégico & Comunica \\
\hline 7. & Autoriza & 7. Componentes & 7. Selecciona y optimiza \\
\hline 8. & $\begin{array}{l}\text { Determina y comunica la aversión al riesgo } \\
\text { y los umbrales }\end{array}$ & 8. Riesgos & $\begin{array}{l}\text { 8. Identifica y gestiona los riesgoso } \\
\text { problemas }\end{array}$ \\
\hline 9. & Solicita, revisa y autoriza & 9. Fondos y recursos & 9. Identifica y solicita \\
\hline 10. & Aprueba, cierra o cancela & 10. Proyecto & $\begin{array}{l}\text { 10. Recomienda aprobación, cierreo } \\
\text { cancelación }\end{array}$ \\
\hline 11. & Determina y aprueba & $\begin{array}{l}\text { 11. Roles, responsabilidad y autoridades para } \\
\text { toma de decisión }\end{array}$ & 11. Recomienda y comunica \\
\hline 12. & Aprueba & $\begin{array}{l}\text { 12. Actas de constitución, planes u } \\
\text { oportunidades de negocio }\end{array}$ & 12. Crea \\
\hline 13. & Determina o aprueba & 13. Indicadores de desempeño & 13. Monitorea, mide, crea y consolida \\
\hline 14. & Revisay aprueba & 14. Plan de trabajo integrado (roadmap) & 14. Crea y actualiza \\
\hline 15. & Revisa, aprueba o autoriza & 15. Portones de fase o revisiones & 15. Gestiona \\
\hline 16. & Autoriza & 16. Auditoría & 16. Conduce \\
\hline 17. & Revisa y aprueba & 17. Gestión de cambio organizacional & 17. Define e implementa los planes \\
\hline 18. & Revisa y aprueba & 18. Metodología de proyecto & 18. Comunica y se adhiere \\
\hline 19. & Responsable (accountable) & 19. Resultados del proyecto & 19. Responsable (responsible) \\
\hline
\end{tabular}

Figura 1. Diferencias funcionales entre la gobernanza y la dirección de proyectos. Elaboración propia con base en PMI (2016). 


\section{Contexto pestroo,cy,yanoss.s.}

Un enfoque para lograr una gobernabilidad efectiva es a través de la mejora continua, que es una estrategia en la que las organizaciones desarrollan la capacidad de lograr estándares más altos y ajustarse a las condiciones cambiantes, al implementar mejoras en los ciclos de gestión en curso. La mejora continua requiere una estrategia y un plan de gestión del cambio organizacional estructurado, que incluye la implementación de sistemas de recompensa, la participación de las partes interesadas y adaptación de las comunicaciones a cada parte interesada para garantizar que los cambios sean divulgados, efectivos y sostenibles.

\section{Balanced Scorecard (BSC o Cuadro de Mando Integral)}

De acuerdo con Kaplan \& Norton (1992), el cuadro de mando integral indica cómo decidir sobre lo que debe ser medido, cuáles son los factores claves de la estrategia y cómo dicha información debe ser dispuesta para que se pueda tener mayor utilidad en la gestión del negocio. Según Kaplan \& Norton (1992), la lógica del método BSC debe poseer como componentes: objetivos estratégicos, lo que implica la traducción de la visión de futuro en objetivos organizados en relación de causa y efecto; indicadores claves de desempeño, es decir, cómo se mide y se acompaña el éxito de cada objetivo; establecimiento de metas a lo largo del tiempo, que se refiere al nivel de desempeño esperado o a la tasa de mejoría necesaria para cada indicador, plan de acción, y proyectos estratégicos, asociados con las metas dispuestas, los planes de acción y los proyectos que deberían ser establecidos a fin de viabilizar su alcance.

El BSC se compone de cuatro perspectivas de negocio (financiera, de cliente, de procesos internos y de aprendizaje), que, al ser analizadas una por una, brindan una mirada independiente del campo por evaluar, pero que, al conjugarse en el marco propuesto por esta herramienta, proveen un panorama holístico del desempeño organizacional.

\section{Políticas}

Una política es una declaración de alto nivel en la que se define un lineamiento específico y claro. Las organizaciones las establecen como una normatividad específica que direcciona el accionar en los procesos y procedimientos, mediante el detalle de lo que se puede y de lo que no se puede hacer. La alta dirección las aprueba con el fin de plasmar sus intenciones en la gestión general y el funcionamiento de la organización (Nakamura, 1987). 
Una gobernanza efectiva de proyectos de principio a fin supone un articulación directa con las políticas de la compañía, para lo cual, en primera instancia, deben existir unas políticas propias sobre los diversos temas que deben ser regulados en la organización, para lo que se debe dar por hecho que estén definidas, implementadas y divulgadas ante todos los interesados, para dar directrices sobre lo que se debe tener en cuenta como precedente para la gestión de proyectos, programas y portafolios organizacionales. Por otra parte, se pueden definir políticas enmarcadas por los lineamientos y las normativas propias de la gestión de proyectos, lo que implica que la toma de decisiones está supeditada a dichas políticas, que son una herramienta que debe ser tenida en cuenta para anticiparse, entender y elegir las medidas y decisiones correctas en la gestión de proyectos que contemplen la intención y sus consecuencias (Shaw, 2003).

\section{Responsabilidad Social Empresarial (RSE) y sostenibilidad}

Según la norma ISO 26000, la RSE se define como la "responsabilidad de una organización ante los impactos que sus decisiones y actividades ocasionan en la sociedad y el medio ambiente, mediante un comportamiento ético y transparente" (International Organization for Standardization (ISO), 2010).

La responsabilidad empresarial cubre tres dimensiones: desempeño económico, administración ambiental e inversión social. En este aspecto, el teórico John Elkington (Como se citó en Wilenius, 2004) sugirió un modelo triangular de responsabilidad empresarial, usado en diferentes organizaciones como herramienta para balancear las metas netamente económicas con una visión social y ambiental.

La sostenibilidad es un concepto que busca un equilibrio entre lo económico, social y ambiental. Las organizaciones tienen como meta el balance entre la creación de riqueza y el uso de los diferentes recursos humanos, materiales, naturales y económicos. Por lo tanto, una empresa es sostenible cuando tiene la capacidad de asegurar su continuidad y posicionamiento a largo plazo; además de contribuir al progreso de las generaciones presentes y futuras. En la actualidad, es frecuente que más interesados asocian la RSE con la ética y las buenas prácticas, en tanto consideran a la sostenibilidad como un término integral de las tres esferas en la cadena de valor. Esta dualidad termina con la conclusión de que la RSE es uno de los medios y la sostenibilidad es el fin al que quiere llegar la organización (Caro, 2017). 


\section{Contexto Restroo, c.y rearosos.s.}

La responsabilidad social empresarial, en la dirección de proyectos, tiene su génesis en la necesidad que existe en el medio de trasladar la RSE al área o a la gerencia de ejecución proyectos de cualquier corporación y verificar si, en efecto, se están dando las condiciones apropiadas en el relacionamiento con los diferentes actores que puedan llegar en un momento dado a participar en la ejecución de proyectos (Restrepo Carvajal y Alzate Monsalve, 2013).

Resulta claro, entonces, que, aunque los aspectos de sostenibilidad y su impacto no estén plenamente reconocidos e involucrados en los diversos estándares de gestión de proyectos, las organizaciones, mediante la utilización de herramientas que faciliten la incorporación de tales aspectos, puedan adelantar una gobernanza y una gestión de proyectos sostenibles que subyace en cada grupo de procesos y que se traduce en la minimización de los recursos utilizados en el ciclo de vida del proyecto (Deland, 2009). Lo anterior se traduce en que debe considerarse el impacto económico, social y ambiental de los proyectos, su resultado y efecto en las generaciones presentes y en el futuro a partir de estrategias claras de gestión del cambio que abarquen definiciones en las políticas, los activos y los demás componentes organizacionales (Silvius et al., 2012).

\section{Metodología}

Se llevó a cabo una investigación exploratoria que permitió construir una visión general de lo que es un modelo de gobernanza efectivo que apalanque la gestión de una oficina de gerenciamiento de proyectos. Para ello se hizo una revisión bibliográfica que posibilitó establecer un marco de referencia; de igual manera, permitió identificar los criterios para el diseño de lo siguiente: modelo de gobernanza, oficina de gerenciamiento de proyectos, esquema de selección y priorización de proyectos y cuadro de mando integral.

La pesquisa bibliográfica y documental se hizo mediante la revisión de algunas publicaciones en revistas y trabajos de investigación que han salido en los últimos 30 años (Tabla 2). La base documental permitió hacer un recorrido histórico y referenciar las proposiciones y datos más importantes de diferentes autores; por otra parte, se localizaron diferentes modelos que desarrollan la gerencia estratégica de proyectos desde diferentes puntos de vista, así como los elementos primordiales para desarrollar una oficina de gerenciamiento de proyectos y un modelo de gobierno que lo soporte, siempre con enfoque hacia el sector de consumo masivo. 
Tabla 2

Bases de datos bibliográficos utilizadas en el desarrollo del trabajo de grado

\begin{tabular}{|c|c|c|c|c|c|}
\hline $\begin{array}{l}\text { Nombre de la } \\
\text { base de datos } \\
\text { bibliográficos }\end{array}$ & $\begin{array}{l}\text { Número } \\
\text { de fuentes } \\
\text { usadas }\end{array}$ & $\begin{array}{l}\text { Número de } \\
\text { fuentes } \\
\text { consultadas }\end{array}$ & $\begin{array}{c}\text { Palabras } \\
\text { claves }\end{array}$ & $\begin{array}{l}\text { Período } \\
\text { de } \\
\text { análisis }\end{array}$ & $\begin{array}{c}\text { Sectores } \\
\text { económicos } \\
\text { aplicables }\end{array}$ \\
\hline $\begin{array}{c}\text { Business Source } \\
\text { Complete } \\
(\text { Ebsco })\end{array}$ & 3 & 8 & \multirow{6}{*}{$\begin{array}{c}\text { Proyectos } \\
\text { Estrategia } \\
\text { Gobernanza } \\
\text { Gerencia } \\
\text { Organización }\end{array}$} & \multirow{6}{*}{$\begin{array}{l}1990- \\
2020\end{array}$} & \multirow{6}{*}{$\begin{array}{c}\text { Consumo } \\
\text { Masivo } \\
\text { Tecnología } \\
\text { Servicios en } \\
\text { general }\end{array}$} \\
\hline Emerald & 5 & 12 & & & \\
\hline Scielo & 4 & 5 & & & \\
\hline Science Direct & 7 & 15 & & & \\
\hline Scopus & 2 & 4 & & & \\
\hline $\begin{array}{c}\text { Web of Science } \\
(\text { WOS })\end{array}$ & 2 & 4 & & & \\
\hline
\end{tabular}

Elaboración propia.

Para el análisis y la definición de las variables del modelo de gobernanza se utilizó el método Delphi con dos paneles de expertos, que hacen parte de empresas del sector de consumo masivo en Colombia. Dichos paneles estuvieron conformados así: el primer grupo por el Comité Corporativo (once personas que conforman el ente rector de la gobernanza de proyectos, que son la primera y segunda línea de mando de la organización, llamados a definir y aprobar los lineamientos y políticas de la organización, definiciones estratégicas y liderazgo y patrocinio de los diferentes portafolios de proyectos de la compañía): gerente general, gerente financiero, gerente de mercadeo, gerente comercial, gerente de nuevos negocios y estrategia (PMO), gerente de desarrollo organizacional, gerente de operaciones y logística, gerente legal y corporativo, gerente administrativo, gerente de manufactura 1 y gerente de manufactura 2.

El segundo grupo estuvo conformado por los gerentes de las Unidades Estratégicas de Negocio (UEN) de la compañía, que dependen de la gerencia de mercadeo (seis personas que se encargan de liderar las seis UEN que son representadas por las grandes marcas de la compañía y que lideran las iniciativas y proyectos propios de cada una). 


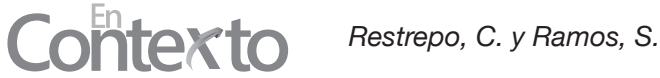

\section{Resultados}

A partir del marco metodológico y teórico, la descripción del problema y los objetivos del trabajo se presentan los siguientes resultados, que agrupan y consolidan la propuesta conceptual propuesta para aplicar en el sector de consumo masivo.

\section{Modelo de gobernanza para la gestión de proyectos}

La gobernanza de proyectos en sí, vista como un sistema compuesto por un conjunto de procesos, les permite a todas las partes interesadas, en especial a la alta gerencia y a la administración, tener información oportuna, relevante, confiable y transparente sobre todas las inversiones empresariales realizadas a través de los proyectos, los programas y los portafolios. De acuerdo con lo anterior, se entiende por la gobernanza de proyectos el ejercicio de autoridad sobre la gestión de los proyectos como un proceso clave y alineado con la estrategia de la compañía, en el que se consideran el ciclo de vida extendido del proyecto y el de vida del producto.

El modelo de gobernanza es desarrollado y liderado por la Oficina de Gerenciamiento de Proyectos (PMO), que se encuentra alojada, en el sentido jerárquico, en el segundo nivel de la estructura organizacional porque depende del presidente (CEO), de modo que se alinee con el cuadro de mando integral y la plataforma estratégica (Figura 2). De igual manera, se entiende que la gestión de portafolios, programas y proyectos que existe en la organización se despliega por medio del relacionamiento y la agrupación de los componentes, con base en su tipología y sus características.

Todo lo anterior se materializa según la sombrilla dispuesta por la gestión organizacional de proyectos (OPM), que fue desarrollada en el apartado del marco teórico, y que tiene como objetivo integrar la gestión de proyectos en un modelo global de rendimiento, que permite gestionar en forma activa los procesos de mejora continua y cambio organizacional para que la organización logre sus objetivos estratégicos. Por último, se plasma la descomposición de la OPM hacia los portafolios, los proyectos y las áreas funcionales de la organización a través de estrategias que potencian las capacidades y recursos de la organización para conducir a una ventaja competitiva sostenible a través de mejores resultados y rendimiento. 

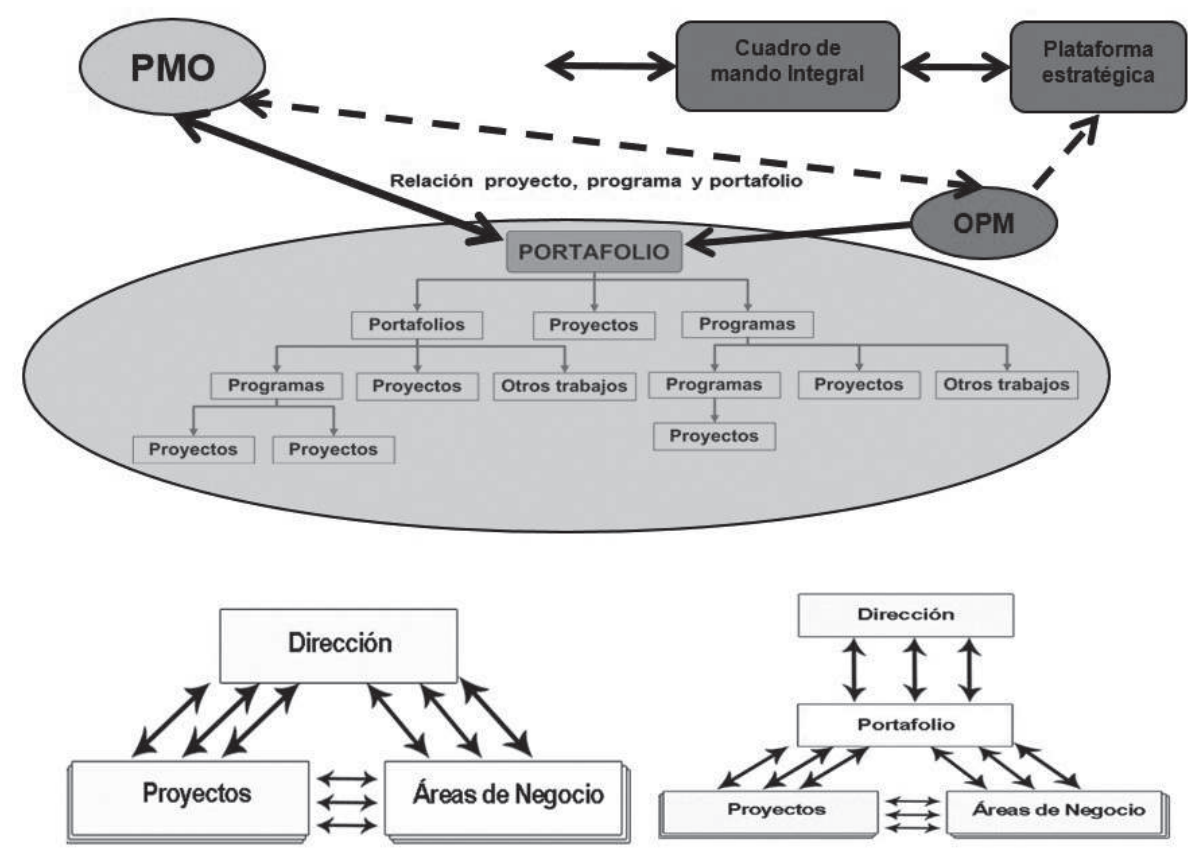

Figura 2. Relación de la PMO con la gobernanza y la gerencia estratégica de proyectos. Elaboración propia.

El modelo de gobernanza (Figura 3) plasma la gobernanza como el centro o corazón del modelo, que se desprende en diferentes aristas, desde las cuales se definen las políticas, el direccionamiento estratégico, la alineación de la organización con la selección de proyectos, el centro de entrenamiento, la implementación de lineamientos de responsabilidad social empresarial y sostenibilidad en la gestión de proyectos y el valor compartido entre la organización y los interesados. Si bien el modelo es una representación gráfica de lo que se espera que sea aplicable para una compañía del sector de consumo masivo, se debe aclarar que su aplicabilidad puede ser expandida a otros sectores de la economía. 


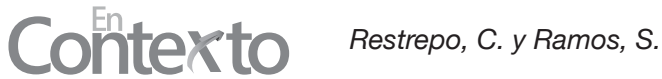

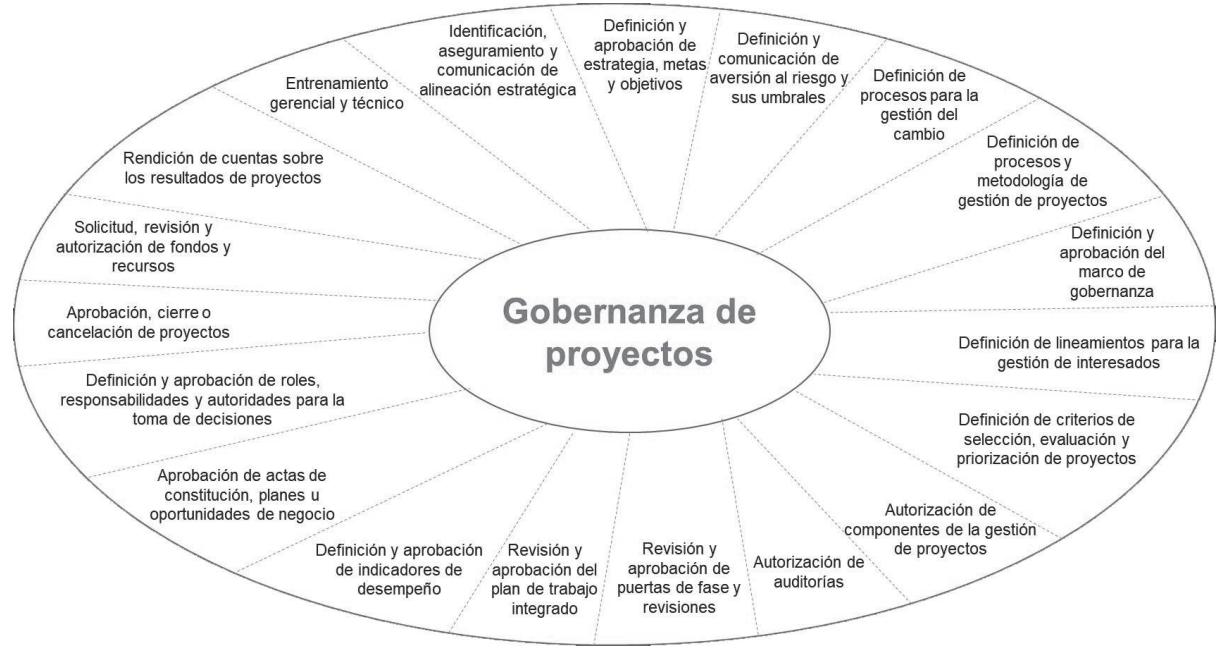

Figura 3. Modelo de gobernanza de proyectos.

Elaboración propia.

\section{Políticas, priorización, selección y evaluación de proyectos}

Una vez entendidas la importancia y relevancia de las políticas corporativas en una organización, que, al ser comprendidas como medio claro y efectivo para legislar y dar a conocer las decisiones de la compañía, la normatividad interna y las condiciones que deben ser cumplidas por todos los empleados, para lo cual se propone el procedimiento de gestión de políticas (Figura 4). 


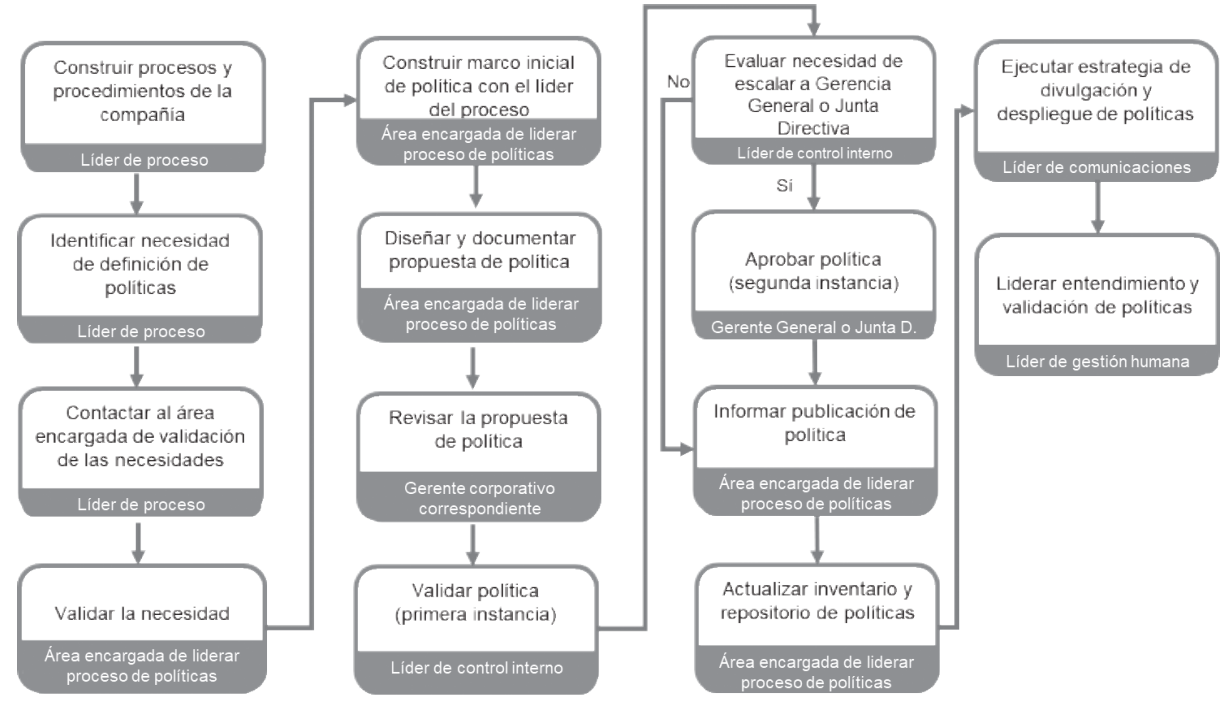

Figura 4. Procedimiento para la gestión de políticas.

Elaboración propia.

La PMO requiere de políticas en consonancia con los componentes del modelo de gobernanza, que brinden los lineamientos para la definición y aplicación de criterios para la evaluación, selección y priorización de proyectos. En primera instancia, dichas políticas deben velar por la construcción e implementación de casos de negocio para evaluar los proyectos potenciales, dado que sin la claridad sobre los parámetros y elementos sobre los cuáles se debe regir la implementación y gestión efectiva de proyectos, sería muy difícil acotar, seleccionar y priorizar todos los proyectos que surgen en la organización. Dicha gestión se compone de las siguientes etapas:

- Identificar el problema de negocio: se usan técnicas creativas para determinar el problema de negocio. Los proyectos tienen un objetivo que debe buscar respuesta a diferentes situaciones presentadas en la organización (las empresas desean resolver sus necesidades a través de los proyectos).

- Identificar alternativas: definir la mejor manera de estructurar el proyecto mediante la consideración de restricciones y supuestos. Para ello se requiere identificar el impacto de cada alternativa planteada (por medio del análisis de restricciones), pronosticar el uso de recursos, definir la pertinencia del proyecto, definir la matriz de riesgos del proyecto y emplear matrices para la identificación de la problemática con mayor impacto ante el problema de negocio (para ello se usan instrumentos como la matriz de Vester). 


\section{Contexto Restrop, c.y yeansos. s.}

- Encontrar la solución: se definen los criterios de valoración a la luz de la estrategia organizacional. Para ello se sugiere definir relaciones entre costo y beneficio para cada alternativa y revisar y definir ponderaciones para cada una con la alineación del plan estratégico.

- Implementar el direccionamiento del proyecto: una vez se tenga claridad sobre el caso de negocio del proyecto, se procede a convencer a los interesados correspondientes. La forma más efectiva para lograr el éxito de los proyectos es mediante la gestión de los interesados (satisfacción $=$ percepciones - expectativas).

Luego de tener claro el caso de negocio y los lineamientos para su construcción, se debe construir una matriz con el compendio, el análisis y la ponderación de las restricciones y las variables para tener en cuenta en la evaluación de proyectos, cuyos criterios y elementos se dan a conocer en la organización como parte de las políticas que deben cumplirse.

Finalmente, dicha definición de lineamientos que quedarán en políticas debe regirse bajo las definiciones arrojadas luego de utilizar el método Delphi con el Comité Corporativo de la Compañía, puesto que esta es una técnica decisora sobre el peso e impacto que tendrán las variables para evaluar los proyectos de ahora en adelante. Para efectos del análisis en empresas de consumo masivo, los resultados obtenidos son los siguientes:

- Caso de negocio: se estableció como el componente básico (mínimo vital) que debe ser desarrollado según la rigurosidad y disciplina metodológica de las etapas presentadas para acotar con claridad el proyecto que debe desarrollarse. A este criterio se le asignó un peso de 14,8\% para la suma ponderada en la matriz para la evaluación, selección y priorización de proyectos.

- Alcance: a partir del alcance definido para cada proyecto propuesto, se clasificaron los proyectos en tres categorías: proyectos de alcance corporativo (que tienen impacto en dos o más vicepresidencias), proyectos de alcance de vicepresidencia y proyectos de alcance de área. Los proyectos corporativos tuvieron una puntuación de tres en este criterio, a los de alcance de vicepresidencia se les asignó una puntación de dos y a los de área se les calificó con uno. A este criterio se le asigna un peso de $10,0 \%$ para la suma ponderada en la matriz para la evaluación, selección y priorización de proyectos. 
- Presupuesto: para clasificar los proyectos con este criterio se definieron tres rangos: 1) Menos de $\$ 800$ millones. 2) Entre $\$ 800$ y $\$ 3.000$ millones. 3) Más de $\$ 3.000$ millones. A este criterio se le asignó un peso de $11,6 \%$ para la suma ponderada en la matriz para la evaluación de proyectos.

- Tiempo (duración): este criterio determina la duración del proyecto por ser evaluado. Para clasificar los proyectos con este criterio se determinaron tres rangos: 1) Menos de seis meses. 2) Entre seis meses y año y medio. 3) Más de año y medio. A este criterio se le asignó un peso de $13,2 \%$ para la suma ponderada en la matriz para la evaluación de proyectos.

- Alineación estratégica: con los proyectos clasificados y evaluados según su impacto sobre los objetivos estratégicos, y con pesos asignados a cada objetivo de la estrategia, se priorizó el portafolio de proyectos. A este criterio se le asignó un peso de 19,7\% para la suma ponderada en la matriz para la evaluación de proyectos.

- Contribución de la gestión de proyectos al flujo de caja de la organización: se validó si el resultado del flujo de caja fue impactado con la gestión del proyecto frente a un escenario en el que no se tuvo en cuenta el impacto o injerencia del proyecto en el flujo de caja. Si existe una contribución, se tiene un resultado de uno, mientras si no la hay es de cero. A este criterio se le asignó un peso de $8,3 \%$ para la suma ponderada en la matriz para la evaluación de proyectos.

- Seguridad: se debe analizar las condiciones de seguridad física (monitoreo y protección de bienes materiales), de las personas, de seguridad y salud en el trabajo, de seguridad de la información y en la cadena de suministro y las demás variaciones de seguridad que sean aplicables y requeridas para garantizar que los riesgos sean mitigados o aceptables, según el apetito de riesgo del proyecto y la organización. A este criterio se le asignó un peso de $5,0 \%$ para la suma ponderada en la matriz para la evaluación de proyectos.

- Ambiental (ecológico) y social (etnográfico): se estudiaron las variables y los factores ambientales (de entorno) que son críticos y relevantes para el logro de los objetivos del proyecto mediante la consideración de las implicaciones a partir de la evaluación ambiental del proyecto y los asuntos de cumplimiento y regulación. El segundo aspecto revisó y estudió las variables sociales y culturales que son críticas para el logro de los objetivos del proyecto, lo que supone una revisión detallada de la interacción con 


\section{Contexto Restreo, , c.y ramos, s.}

los grupos de interés que se relacionan con el proyecto. A este criterio se le asignó un peso de $10,4 \%$ para la suma ponderada en la matriz para la evaluación de proyectos.

- Imagen, marca y reputación: en este análisis se utilizaron técnicas de personificación del proyecto, que se soportan en otorgarle atributos humanos al proyecto, por medio del uso de técnicas del comportamiento del consumidor. A este criterio se le asignó un peso de 7,1\% para la suma ponderada en la matriz para la evaluación de proyectos.

Considerando lo anterior, donde se presentan las diversas variables ponderadas y utilizadas para evaluar proyectos, se constituye una matriz donde se tendrá constancia de la calificación de cada ítem y el resultado final por proyecto evaluado (Tabla 3 ). 


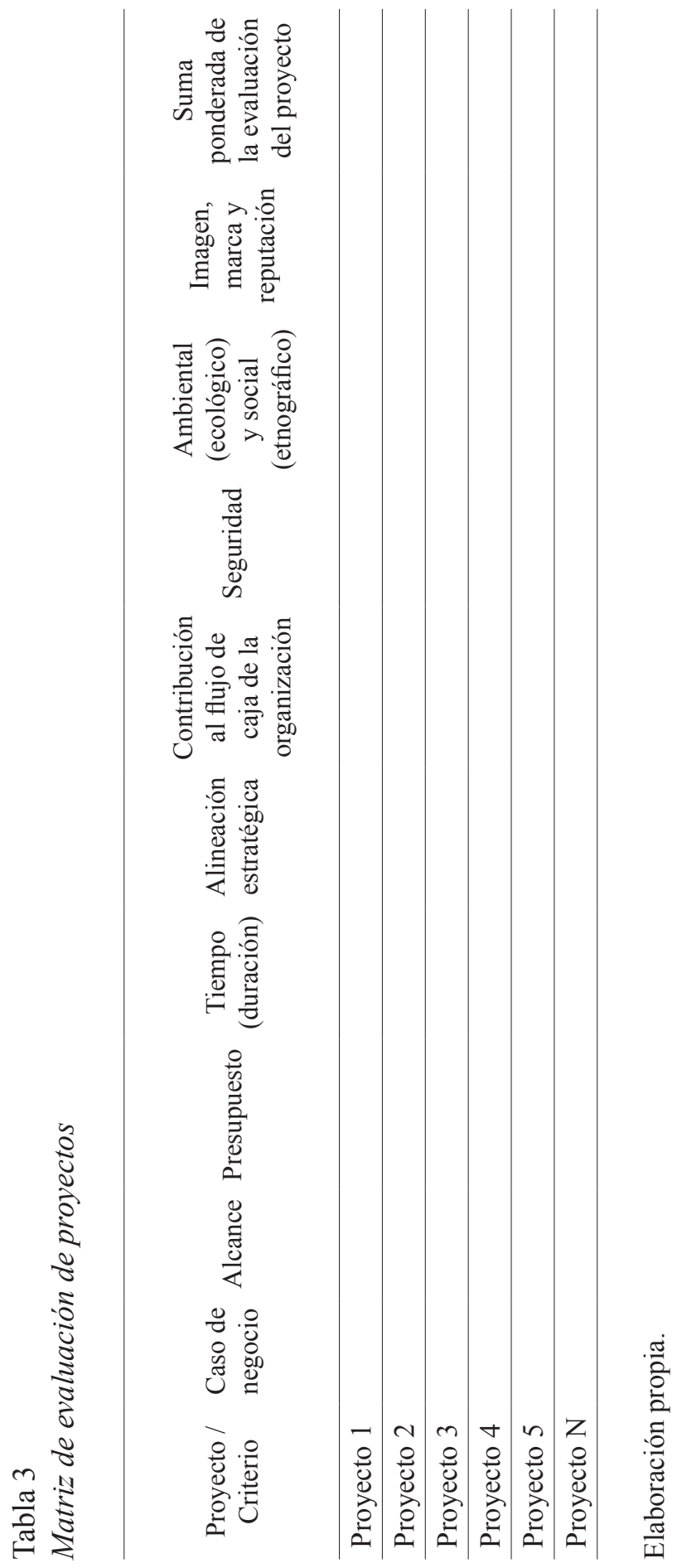




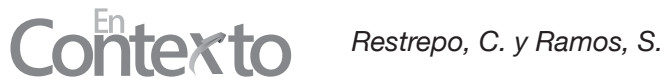

De acuerdo con la ponderación anterior, para definir los proyectos que se ejecutarán se debe lograr una calificación mínima de 80 puntos; por otro lado, los proyectos que tienen una calificación entre 60 y 79 puntos se posponen y los que tienen una puntuación menor que 60 puntos se cancelan (Tabla 4).

Tabla 4

Matriz de priorización y selección de proyectos

\begin{tabular}{cccc}
\hline $\begin{array}{c}\text { Clasificación / } \\
\text { Ponderación }\end{array}$ & Menor que 60 & Entre 60 y 79 & $\begin{array}{c}\text { Mayor que } \\
80\end{array}$ \\
\hline Para ejecución & & & $\mathrm{X}$ \\
\hline Cancelados & $\mathrm{X}$ & & \\
\hline Pospuestos & & $\mathrm{X}$ & \\
\hline
\end{tabular}

Elaboración propia.

\section{Responsabilidad social empresarial (RSE), sostenibilidad y valor compartido en proyectos}

Para efectos del modelo de gobernanza planteado, se percibió la RSE como un medio y la sostenibilidad como un fin. El mapeo de los grupos de interés con sus respectivas necesidades le permite a la organización definir una gestión efectiva sobre ellos (Figura 5), de tal manera que, en consonancia con el caso de negocio del proyecto, se potencie el cumplimiento de los indicadores de desempeño, con inclusión de los de favorecimiento cultural, social y ambiental. Es de resaltar la importancia de incluir los medios de comunicación en las estrategias de participación y gestión del proyecto. 


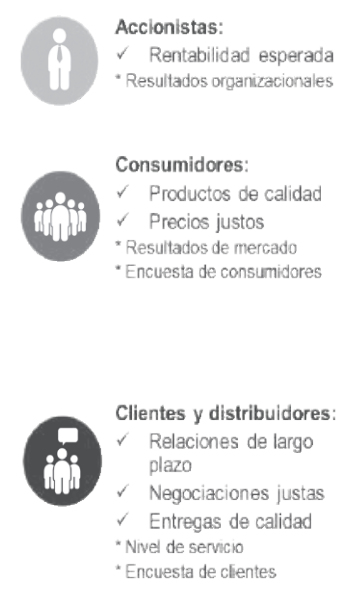

"Esquemas y métodos de verificación
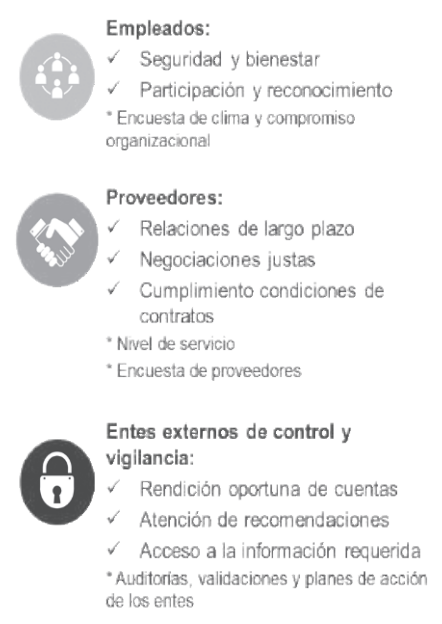

de los entes

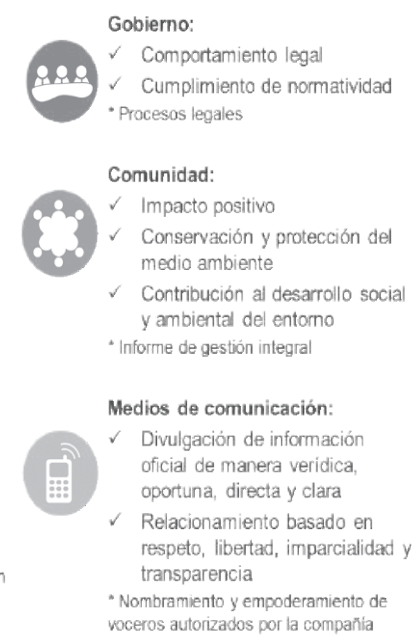

Figura 5. Grupos de interés, compromisos, esquemas y métodos de verificación. Elaboración propia.

En los lineamientos de generación de valor empresarial se necesita una voluntad real por parte de los altos directivos de la organización, debido a que, sin ella, no se pueden lograr beneficios de la relación entre la empresa y los interesados. En este sentido, el valor compartido, como modelo estratégico, es fundamental en la valoración de los efectos e impactos de la compañía en su entorno, y, así mismo, el del entono sobre ella. La gobernanza de proyectos materializa el valor compartido organizacional a la hora de concebir proyectos orientados a:

- Renovar los productos y mercados existentes en el sector de consumo masivo.

- Redefinir la productividad en la cadena de valor (procesos que definen y explican la gestión de la compañía), siempre con la intención de buscar la eficiencia y la optimización organizacional.

- Permitir el desarrollo de un conglomerado local, con el que estén relacionadas diversas empresas del mismo sector de consumo masivo, que puedan hacer sinergias y alianzas y tener una sana competencia.

Las definiciones y los elementos claves presentados por la RSE, la sostenibilidad y valor compartido se enmarcan en un modelo (Figura 6), que permite orientar a cualquier persona que haga parte de la organización y, aún más, que tenga algún tipo de participación en la gestión de proyectos sobre sus responsabilidades, límites y entregables. 


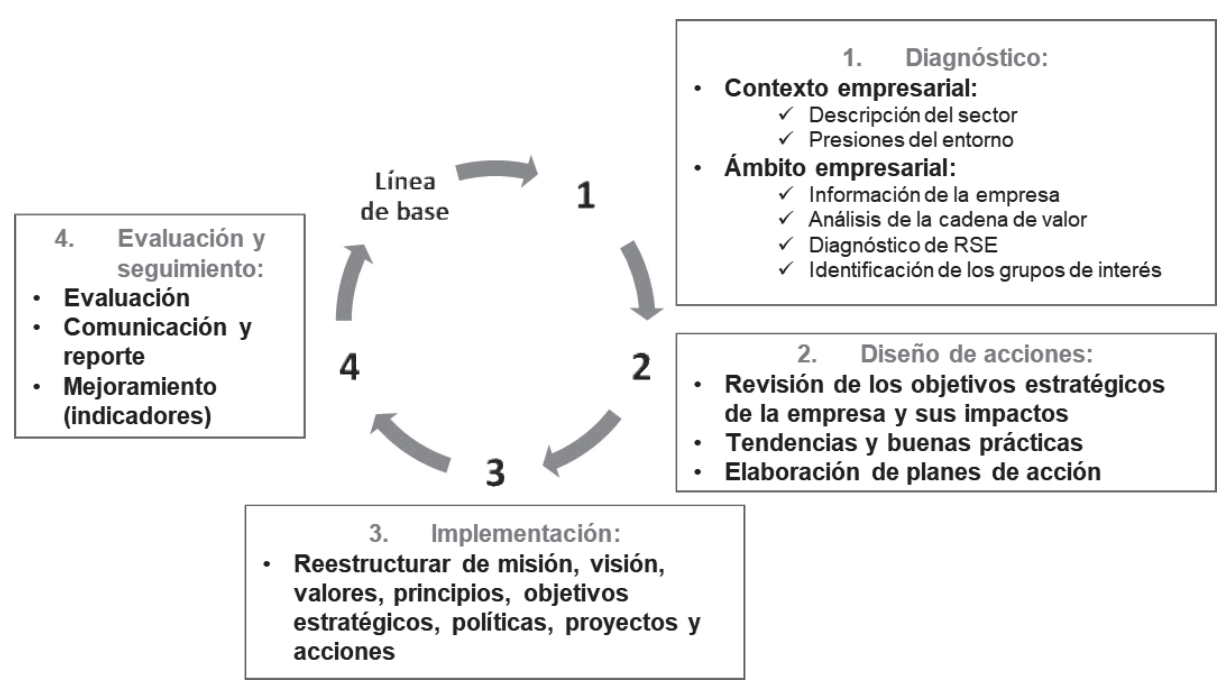

Figura 6. Modelo de RSE, sostenibilidad y valor compartido.

Elaboración propia con base en la Universidad Externado de Colombia, Facultad de Administración de Empresas (2015).

La relevancia en la definición de lineamientos de RSE, sostenibilidad y valor compartido radica en que se establezcan pautas para la gestión de proyectos sostenibles con beneficios de mediano y largo plazo, al considerar la interacción con los diferentes grupos de interés y el impacto, tanto social y ambiental como económico, que se genera por el desarrollo de los proyectos en los que se vean involucrados.

\section{Oficina de gerenciamiento de proyectos (PMO)}

Se constituye una PMO con la misión de implementar procesos transversales para la gestión corporativa de proyectos, por medio de la definición de lineamientos, procedimientos y herramientas que permitan una óptima planeación, medición y control, con el fin de contribuir al cumplimiento de los objetivos estratégicos de la organización y de los proyectos. Además, tiene como propósito brindar apoyo metodológico a las diferentes áreas de la organización, de modo que se permita el logro de una tasa de éxito superior al $90 \%$ en la ejecución de proyectos de la organización mediante el suministro de herramientas estándar, capacitación y acompañamiento a todos los empleados y grupos de interés requeridos. 


\section{Funciones de la PMO}

- Monitorear y controlar el desempeño en las diferentes etapas de los proyectos a través de un tablero de control (cuadro de mando integral) de proyectos que pueda ser visualizado por el equipo directivo de la organización y del proyecto, con el fin de dar alertas tempranas y favorecer la toma de decisiones. El cuadro de mando integral propuesto se compone de cinco perspectivas estratégicas: financiera, aprendizaje y personas, entorno, negocios y excelencia y productividad, que tienen una ponderación igual $(20 \%$ por cada perspectiva) a la hora de evaluar el desempeño total del tablero.

- Diseñar y promover la implementación de los procesos concernientes a la gestión de proyectos por medio de la definición de lineamientos, procedimientos y herramientas que permitan la planificación, ejecución, control y cierre efectivo de proyectos.

\section{Estructura de la PMO}

La estructura organizacional de la PMO depende de manera directa de la Presidencia y está conformada por recursos de tiempo completo y un líder de la vicepresidencia (área funcional) que soporta la estrategia y gestión de proyectos en la organización (Figura 7). Además, existen líderes de proyectos que pertenecen a las diferentes áreas funcionales de la compañía, que cumplen la función de ser satélites y portavoces de las metodologías y los lineamientos definidos, así como de encargarse del monitoreo y liderazgo de algunos proyectos. 


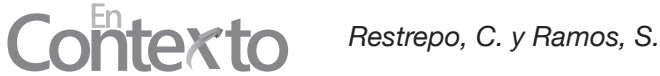

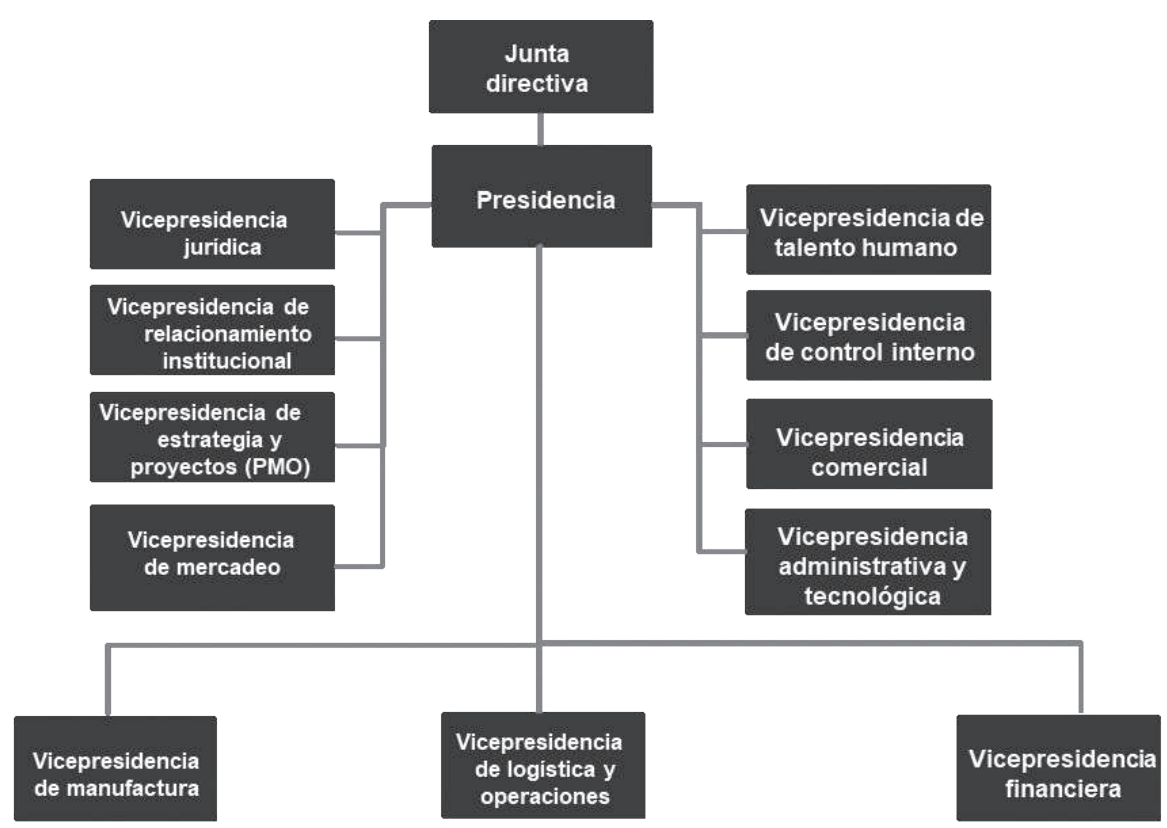

Figura 7. Estructura organizacional de primer y segundo niveles con inclusión de la PMO.

Elaboración propia.

Vicepresidente corporativo de Estrategia y Proyectos: encargado de liderar el área funcional de estrategia y proyectos de la compañía; vela por consolidar y promover las definiciones metodológicas de estrategia y por monitorear el cumplimiento y despliegue de la plataforma estratégica corporativa. Lo anterior, mediante la promoción y liderazgo de la correcta gestión de portafolios, programas y proyectos de la compañía por ser el encargado de custodiar el cumplimiento de la misión de la PMO.

Perfil: Profesional con conocimientos y habilidades en gerencia estratégica, gerencia del talento humano, gerencia de proyectos y procesos. Debe contar con ocho años de experiencia en gestión de proyectos, gestión estratégica y liderazgo de equipos.

Líder de proyectos: es el responsable del acompañamiento metodológico de los gerentes de proyectos de las diversas áreas con el fin de garantizar que se utilicen todos los artefactos desarrollados y que se apliquen los procesos estándar. Este líder es un directivo con poder moderado en la cadena de mando. 
Perfil: profesional con experiencia en gerencia de proyectos, formulación de proyectos y talento humano. Debe contar con seis años de experiencia en gestión de proyectos y estandarización de procesos.

\section{Estrategia de implementación de la PMO}

De acuerdo con el nivel de madurez de la gestión de proyectos de diferentes compañías del sector de consumo masivo, el marco teórico y los antecedentes revisados y las necesidades del sector, se definió que la Oficina de Proyectos debe ser una PMO corporativa que integre la gestión de proyectos con los intereses de negocio. Con base en los tres modelos de Casey \& Peck (2001), la mencionada PMO incorpora una conducta de "torre de control" debido a que estandariza procedimientos para la gestión de proyectos y brinda acompañamiento a la aplicación de dichos lineamientos. Este proceso de implementación y consolidación de la PMO se lleva a cabo en cinco fases (Figura 8).

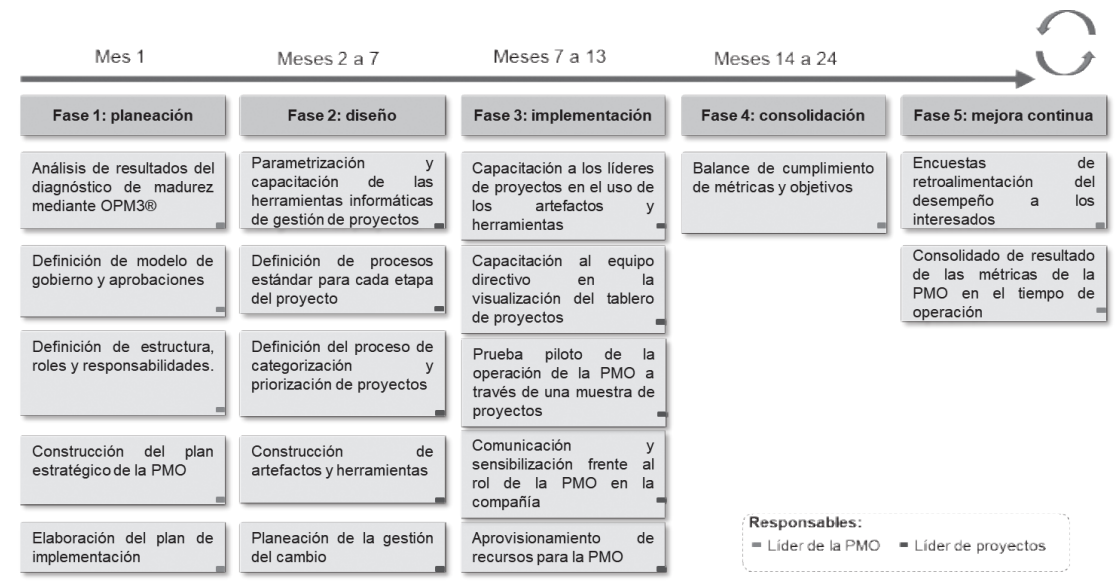

Figura 8. Estrategia de implementación de la PMO.

Elaboración propia.

\section{Monitoreo del modelo de gobernanza}

\section{Estrategia corporativa}

Para determinar con claridad el impacto y la razón de ser de una PMO que soporte y brinde resultados de valor, coherentes con los recursos, las capacidades y los elementos organizacionales, se requiere definir un modelo de negocio y un análisis de escenarios que permitan visualizar con nitidez cómo se apalanca la estrategia a partir de la estructura propuesta de gerenciamiento de proyectos. 


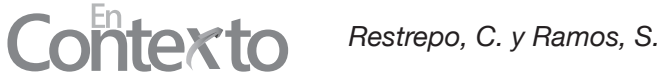

\section{Perspectivas estratégicas}

Las perspectivas estratégicas consolidan los objetivos estratégicos de la organización, que son las metas de máximo nivel acotadas que determinan lo que en realidad es importante para orientar la organización. Las perspectivas estratégicas se apoyan en metodologías como el Balanced Scorecard (BSC) para agrupar dichos objetivos y permitir demostrar en unos pocos eslabones cómo se va a materializar, alinear y desplegar la estrategia en la organización; las perspectivas más comunes y definidas para el sector de consumo masivo son:

- Financiera: alcanzar los resultados con el fin de garantizar rentabilidad para los accionistas.

- De aprendizaje y personas: velar por el desarrollo y el bienestar de los empleados.

- De entorno: alcanzar la sostenibilidad de acuerdo con los enfoques social y ambiental a partir de acciones responsables y coherentes que viabilicen el óptimo desarrollo del entorno.

- De negocios: entregar conceptos y soluciones que generen satisfacción y bienestar al consumidor, apalancados en marcas líderes en el mercado en el que se tiene presencia.

- Excelencia y productividad: incrementar la productividad del negocio con el propósito de buscar sinergia y optimización de procesos.

Si bien la innovación no es una perspectiva estratégica, la declaración organizacional sobre ella busca que se consolide como un pilar fundamental para el desarrollo y evolución de la compañía, con el fin de garantizar competitividad para ser líderes en el mercado. Por ser un eje transversal y corporativo, cada área de gestión es responsable por favorecer la disrupción, la mejora y el cambio en los procesos.

\section{Métricas de gestión}

Los Key Performance Indicators (KPI) que se implementen deben permitir a la organización determinar si la PMO aporta valor al cumplimiento de los objetivos estratégicos por medio de la validación de la importancia y la pertinencia que brindan los procesos, los artefactos y métodos que se implementen para direccionar y llevar por buen camino el desarrollo del portafolio de proyectos. Es usual que, antes de la PMO, la organización no posea datos asociados con mediciones de rendimiento, o, si los hay, no son confiables debido a que su procesamiento no estaba estandarizado en la organización. Por esta razón, la 
organización debe diseñar e implementar un sistema de gerenciamiento de la información, cuyas funciones son las siguientes:

- Registro, almacenamiento y actualización de los atributos y las características de todos los entregables de los proyectos, lo que permite la validación del alcance, el control de la calidad y el cierre de etapas de cada proyecto.

- Desarrollo del sistema de autorización de trabajo (SAT), mediante el que se define el cuándo y la secuencia de las actividades de cada uno de los proyectos.

- Registro, trazabilidad y actualización del registro de solicitudes de cambio del proyecto. En este caso se opta por la conformación de un comité integrado de cambios, como responsable de esta función; se debe procurar que esté conformado por personal externo (mayoría de integrantes) e interno al proyecto.

Los KPI deben ser medibles en términos financieros y de negocio, de tal manera que puedan ser captados y aprovechados por el Comité Corporativo para una adecuada toma de decisiones. Dado lo expuesto, se definieron los siguientes indicadores:

\section{- Cumplimiento en diagrama de hitos}

Objetivo: demostrar cómo una adecuada gestión de proyectos, con el acompañamiento de la $\mathrm{PMO}$, permite cumplir o mejorar los tiempos de entrega de proyectos.

Métrica: duración real de la ejecución del proyecto/duración estimada de la ejecución del proyecto.

Meta: desviación en el cumplimiento de cronogramas de proyectos menor que 10\%.

Periodicidad: mensual.

\section{- Cumplimiento en la ejecución del presupuesto de proyectos}

Objetivo: demostrarcómo unaadecuadagestión proyectos, conelacompañamiento de la PMO, permite cumplir o mejorar la ejecución de presupuestos.

Métrica: costo real de la ejecución de los proyectos/costo estimado de la ejecución de los proyectos.

Meta: desviación en el cumplimiento de presupuestos de proyectos menor que 10\%. Periodicidad: mensual. 


\section{Contexto pestroo,cy,yanoss.s.}

\section{- Porcentaje de proyectos que sufren corrupción en el alcance (se refiere al incumplimiento en el logro del alcance del proyecto y sus productos)}

Objetivo: definir el incumplimiento de los alcances de los entregables del proyecto, mediante el uso del sistema de gerenciamiento de la información del proyecto.

Métrica: número de atributos del proyecto corruptos/número de atributos totales. Meta: cero corrupciones del alcance.

Periodicidad: mensual.

\section{- Satisfacción de los interesados por el cumplimiento de los entregables}

Objetivo: evaluar la percepción y satisfacción de los grupos de interés relacionados con la gestión de proyectos, programas y portafolios a través de encuestas en las que se califican parámetros cualitativos por medio de escalas de evaluación conceptual o escalas de orden de rango.

Métrica: satisfacción $=$ percepciones-expectativas .

Meta: 95\%.

Periodicidad: trimestral.

\section{- Ahorros por sinergias de recursos}

Objetivo: evaluar, a través de un adecuado análisis y optimización del costo de los recursos humanos, físicos, tecnológicos y financieros cómo se impacta de manera positiva su uso en las distintas áreas.

Métricas: (costos optimizados (con eficiencias) de recursos físicos + recursos humanos + recursos tecnológicos + recursos financieros) / (costos totales asignados (presupuestados) de recursos físicos + recursos humanos + recursos tecnológicos + recursos financieros).

Meta: porcentaje de optimización mayor que $10 \%$.

Periodicidad: trimestral.

\section{Conclusiones}

Desde el marco teórico se extrae la importancia y los fundamentos requeridos para definir un modelo de gobernanza de proyectos que, por su importancia, termina siendo la pieza fundamental para soportar la gestión estratégica de proyectos de una organización.

Para el diseño de una PMO, se debe contar con lineamientos que incluyan políticas e integración con la RSE, la sostenibilidad y el valor compartido; según los cuales, el modelo de gobernanza de proyectos tendrá vida a nivel organizacional, puesto que funciona como un sistema compuesto por un 
conjunto de procesos que les permite a todas las partes interesadas, en especial a la alta gerencia y a la administración, tener información oportuna, relevante, confiable y transparente sobre todas las inversiones empresariales realizadas a través de los proyectos, los programas y los portafolios.

La PMO debe proveer lineamientos, herramientas y procedimientos que les permitan a los líderes y equipos de proyectos realizar una adecuada gestión de los riesgos, restricciones y recursos de la organización. Esta gestión debe estar soportada en un modelo de gobernanza claro, interiorizado y socializado, con patrocinio e interés total de la Presidencia y del Comité Corporativo.

La implementación de la PMO permite centralizar proyectos y consolidarlos en un portafolio corporativo orientado a la disminución de sobrecostos generados por la duplicidad de esfuerzos en diferentes áreas de la compañía; además, favorece la capacidad de negociación y el logro de economías de escala.

La PMO debe liderar la evaluación, selección y priorización de proyectos al considerar diversos aspectos y criterios que, al ser ponderados, evidencien coherencia organizacional, sustentos medibles y comparables, contundencia y aplicación real de un modelo de gobernanza que vele por la alineación y el cumplimiento de la estrategia y de las restricciones, que respete el caso de negocio construido y que contribuya al flujo de caja de la organización.

Es fundamental alinear los compromisos y las características de todos los grupos de interés que hacen parte de las esferas sociales, económicas y ambientales en las que se desempeña la compañía para cumplir los objetivos del relacionamiento establecidos con dichos grupos de interés a través de proyectos o iniciativas que sean consecuentes y contundentes con los esquemas de validación, seguimiento y desempeño frente a los objetivos pactados.

El modelo de gobernanza planteado establece que la RSE es la responsabilidad de la empresa por su impacto en la sociedad (con inclusión de elementos de ética y buenas prácticas), mientras que la sostenibilidad es el impacto que se da en las esferas sociales, económicas y ambientales desde el punto de vista de la cadena de valor. Por lo tanto, se concluye que la RSE se ha de ver como un medio y la sostenibilidad como un fin al que quiere llegar la empresa.

Finalmente, se concluye la tendencia de buscar la efectividad organizacional a partir del monitoreo del modelo de gobernanza adoptado por la organización, lo que se validó con la alineación del caso de negocio de los proyectos, el análisis y los planes de acción derivados de los resultados de las métricas establecidas para evaluar los proyectos organizacionales y los mecanismos de seguimiento respecto a las diferentes instancias que se requieran. 


\section{Referencias}

Caro, G. (2017). La RSE y la sostenibilidad. Stratego. http://www.stratego. com.pa/la-rse-y-la-sostenibilidad/

Casey, W., \& Peck, W. (2001). Choosing the right PMO setup. PM Network, 15(2), 40-47. https://www.pmi.org/learning/library/choosing-rightproject-management-office-setup-3496

Crawford, J., Cabanis-Brewin, J., \& Pennypacker, J. (2008). Seven steps to strategy execution. Integrating portfolios, programs, projects and people for organizational performance. Project Management Solutions. http://pmbooks.pmguruonline.com/PDF/Seven_Steps_to_Startegy_ Exceution.pdf

Deland, D. (13 de octubre de 2009). Sustainability through project management and net impact. Conferencia en PMI $\square$ Global Congress Proceedings North America, Orlando, Fl. Newton Square, PA: PMI. http://www.pmi. org/learning/sustainability-goals-achievingframework-technique-6776

Fernández Carazo, A., Gómez Núñez, T., Guerrero Casas, M., y Caballero Fernández, R. (2008). Evaluación y clasificación de las técnicas utilizadas por las organizaciones, en las últimas décadas, para seleccionar proyectos. Revista de Métodos Cuantitativos para la Economía y la Empresa, 5, 67115. http://www.upo.es/RevMetCuant/art20.pdf

Hill, G. (2004). Evolving the project management office: a competency continuum. Information System Management, 21(4), 45-51. DOI: 10.120 1/1078/44705.21.4.20040901/84187.6

International Organization for Standardization. (ISO). (2010). ISO 26000. Social responsibility. ISO. https://www.iso.org/iso-26000-social-responsibility.html

Kaplan, R., \& Norton, P. (1992). The balanced scorecard - Measures that drive performance. Harvard Business Review, 70(1), 71-79. https://hbr. org/1992/01/the-balanced-scorecard-measures-that-drive-performance-2

Nakamura, R. (1987). The textbook policy process and implementation research. Review of Policy Research, 7(1), 142-154. DOI: 10.1111/ j.1541-1338.1987.tb00034.x

Project Management Institute.(PMI). (2013). Managing change in organizations: A practice guide. PMI. https://www.pmi.org/pmbok-guide-standards/ practice-guides/change

Project Management Institute. (PMI). (2016). Governance of portfolios, programs, and projects: a practice guide. PMI. https://www.pmi.org/ pmbok-guide-standards/practice-guides/governance 
Project Management Institute. (PMI). (2017a). Project management body of knowledge, PMBok $\square$ guide. PMI.

Project Management Institute. (PMI). (2017b). The standard for portfolio management. PMI.

Restrepo Carvajal, C., y Alzate Monsalve, A. (2013). Aproximación a la responsabilidad social corporativa, con énfasis en el direccionamiento de proyectos. Ciencias Estratégicas, 21(29), 69-85. https://revistas.upb. edu.co/index.php/cienciasestrategicas/article/view/2457/2141

Shaw, J. (2003). Corporate governance and risk: a systems approach. Wiley Finance.

Silvius, A., Van Den Brink, J., \& Köhler, A. (2012). The impact of sustainability on project management. En A. Silvius, J. Van Den Brink \& A. Köhler (Ed.), The project as a social system: Asia-Pacific perspectives on project management. Monash University Publishing. http://books.publishing.monash.edu/apps/ bookworm/view/The+Project+as $+\mathrm{a}+$ Social + System $\% 3 \mathrm{~A}+$ Asia-Pacific + Pe rspectives+on+Project+Management/171/OEBPS/c11.htm

Srivannaboon, S., \& Milosevic, D. (2006). A two-way influence between strategy and project management. International Journal of Project Management, 24(6), 493-505. DOI: 10.1016/j.ijproman.2006.03.006

Universidad Externado de Colombia, Facultad de Administración de Empresas (2015). Modelo de gestión de RSE para empresas. Universidad Externado de Colombia, Facultad de Administración de Empresas. http://admon.uexternado.edu.co/matdi/Otros/responsabilidadSocial/ herramientas/1.\%20Modelo\%20General.pdf

Wessels, D. (2007). The strategic role of project management. PM World Today, 9(2), 1-9. http://www.pmworldtoday.net/

Wilenius, M. (2004). Towards the age of corporate responsibility? Emerging challenges for the business world. Futures, 37(2-3), 133-150. DOI: $10.1016 /$ j.futures.2004.03.034

\section{Para citar este artículo:}

Restrepo, C. y Ramos, S. (2020). La presencia de un modelo de gobernanza en la gerencia estratégica de proyectos: caso aplicable a empresas de consumo masivo. En-Contexto, 8(13), 69-105. 